University of Wollongong

Research Online

Faculty of Arts - Papers (Archive)

Faculty of Arts, Social Sciences \& Humanities

2011

\title{
The effect of Point of Sale Promotions on the alcohol purchasing behaviour of young people in metropolitan, regional and rural Australia
}

Sandra C. Jones

University of Wollongong, sandraj@uow.edu.au

Kylie M. Smith

University of Wollongong, kyliesm@uow.edu.au

Follow this and additional works at: https://ro.uow.edu.au/artspapers

Part of the Arts and Humanities Commons, and the Social and Behavioral Sciences Commons

\section{Recommended Citation}

Jones, Sandra C. and Smith, Kylie M., The effect of Point of Sale Promotions on the alcohol purchasing behaviour of young people in metropolitan, regional and rural Australia 2011, 885-900.

https://ro.uow.edu.au/artspapers/1136

Research Online is the open access institutional repository for the University of Wollongong. For further information contact the UOW Library: research-pubs@uow.edu.au 


\title{
The effect of point of sale promotions on the alcohol purchasing behaviour of young people in metropolitan, regional and rural Australia
}

\author{
Sandra C. Jones* and Kylie M. Smith
}

Centre for Health Initiatives, University of Wollongong, Wollongong, Australia

This study, part of a larger project examining marketing and alcohol, looked specifically at the effects of point of sale (POS) promotions on young people, with a view to providing evidence which could be used to inform policy and regulation in this area. A series of focus groups were conducted in three different locations with young people aged $16 \square 25$ years, separated by age and gender, with a total of 85 participants. Participants were asked questions about their recollection of various POS promotions and the effect of these promotions on their alcohol purchasing and consumption behaviour. The majority of participants indicated a strong link between POS promotions and alcohol purchasing and consumption behaviour. A majority of participants demonstrated a strong recall of previous promotions and almost all participants indicated they had been influenced to buy more or a particular brand of alcohol because of a promotion. Specifically, the results of the study indicate that POS promotions involving price or volume discounts have a strong impact on young people, and are particularly effective in encouraging the purchase of increased volumes of alcohol, suggesting a need for regulation in this area.

Keywords: alcohol; marketing; point of sale; drinking behaviours; consumption; attitudes; media; young adulthood

\section{Introduction}

There is a substantial body of research investigating the links between advertising and alcohol, and the effects of alcohol advertising on young people (Smith and Foxcroft 2009). However, there is very little research into point of sale (POS) marketing for alcohol, and even less research on the effects of this marketing on young peoples' alcohol-related attitudes and behaviours. This study, part of a larger project examining marketing and alcohol, aimed to look specifically at the effects of POS promotions on young people, with a view to providing evidence which could be used to inform policy and regulation in this area. The results of the study indicate that POS promotions have a strong impact on young people, but responses differed depending on the age and location of the groups. Overall, POS promotions involving reduced prices seem particularly effective in encouraging the purchase of increased volumes of alcohol, suggesting a need for regulation in this area.

\section{Alcohol advertising and young people}

There is increasing evidence that young people are heavily exposed to alcohol advertising (e.g. Garfield et al. 2003, Jernigan et al. 2005, King et al. 2005, Jernigan 2006, Center on Alcohol Marketing and Youth 2006a, 2006b). Furthermore, there is a growing body of literature demonstrating associations between reported exposure to, and liking of, alcohol advertising and drinking intentions and behaviours (e.g. Austin and Knaus 2000, Fleming et al. 2004, Stacy et al. 2004, Chen et al. 2005, Ellickson et al. 2005, Snyder et al. 2006, Collins et al. 2007, Hurtz et al. 2007, Pasch et al. 2007, Smith and Foxcroft 2007). POS marketing

Point of sale (POS), or point of purchase (POP), marketing refers to advertising and/ or promotional materials at the point where a purchase will be made. POS marketing is seen as a key strategy for product marketers, with research showing that two-thirds of all purchases result from decisions made while in the store, and $90 \%$ of retail store managers surveyed in the USA agreed that POS materials sell products (Dibb et al. 2001). As well as POS advertising (posters, store signage, window displays, etc.), POS promotions include free product samples, premiums (gifts with purchase), reduced price offers and consumer contests and prizes. POS promotions have been shown to encourage product trial and increase purchase volume (Chipperfield 1996, Gilpin et al. 1997).

While a detailed analysis of the extensive research base on POS marketing is beyond the scope of this article, it is important to note that marketers have a clear understanding of the types of promotions that appeal to consumers. For example, it is well known that consumers respond more favourably to promotions where the premium is provided at the time of sale and when the value of the premium is 
highlighted (d'Astous and Jacob 2002); and price reductions that are framed as providing 'free' product options are perceived more favourably than conventional discounts (Munger and Grewal 2001).

\section{Alcohol POS marketing}

While there is a need to continue research on alcohol advertising, what has largely been neglected is the effect of non-advertising alcohol promotions on people's (and particularly young people's) alcohol-related attitudes and behaviours. By non- advertising, we are referring to marketing communications and promotions that are not disseminated via the media but rather are provided at the point where the actual product is purchased $\square$ these include posters or displays, price (or volume) discounts, gifts, give-aways, branded merchandise and competitions. As the alcohol industry has become increasingly competitive, POS is increasingly being used as a marketing tool for alcohol products, and there is a growing body of evidence suggesting that these POS materials are positively associated with drinking and contribute to creating a pro-alcohol environment (e.g. Howard et al. 2004). According to the trade press in the USA, approximately $60 \%$ of people in bars make their decision about what to drink after they arrive (Brabbs 2002) and the role of POS is to 'grab their attention and make them aware that a particular brand is just what they want' (Solley 2000, p. 41).

It is well known by alcohol retailers themselves that POS promotions can play a significant part in alcohol purchasing behaviours. For example, the British Beer and Pub Association's Good Practice Guide for Pub Owners and Licensees (British Beer and Pub Association, 2002) advises publicans that POS promotions 'can be a valuable marketing tool for enhancing product awareness among customers, but they can also be fun, giving customers the opportunity to win competition prizes or buy a new or favourite drink at a reduced price' (p. 3). They also give a list of reasons for holding POS promotions (including to boost trade during quiet periods, and to showcase a new brand). Interestingly, they also caution that while 'promotions can give a pub a competitive edge ... if badly managed or directed, they can also sometimes be perceived as encouraging customers to drink too much, and therefore as a contributory factor to public order problems' (p. 3). This knowledge indicates the significance of POS promotions, and the importance of understanding more about how they work, so that appropriate recommendations for their regulation can be made.

\section{Alcohol POS research}

Of the few studies that have been conducted on non-advertising alcohol marketing, the primary focus has been price promotions. Significantly, there has been very little work on this issue in Australia, but we can draw some basic conclusions from international studies. Firstly, there is considerable evidence that there is an inverse relationship between the price of alcohol and the level of consumption (Levy and Sheflin 1983, Coate and Grossman 1988, Osterberg 1995); and that this effect is even more pronounced among young people (Kenkel 1993, Grossman et al. 1994, Sutton and Godfrey 1995, Chaloupka and Weschler 1996). For example, as early as the 1970s, an experimental study in the USA found that alcohol consumption more than doubled during simulated 'happy hours' among both heavy and light drinkers (Babor et al. 1978).

While the correlation between price and purchasing may be relatively straightfor- ward, other research has found that this is only one factor contributing to alcohol purchasing patterns. For example, Kuo et al. (2003) conducted environmental assessments of neighbourhoods surrounding 119 college campuses across the USA, with a focus on off-premise (e.g. liquor stores, grocery stores, convenience stores) and onpremise (e.g. bars, clubs, restaurants) outlets that sold beer; data were collected from a maximum of 20 off-premise and 8 on-premise outlets in each location (total of 1684 off-premise and 830 on-premise outlets). The study found that for off- premise outlets (e.g. bottle shops) ${ }^{1}$ higher binge-drinking rates were correlated with: the availability of large volumes of beer; lower average price of a carton of beer; interior and exterior advertising; and promotions such as volume discounts, advertised price specials or coupons.

If factors other than price are known to influence purchasing decisions, then it is important to understand how these may affect young people. In a study of alcohol POS advertising and promotions in 10 urban communities in California, Howard et al. (2004) examined exterior advertising and promotions at 523 onpremise outlets (restaurants and bars) and interior and exterior advertising and promotion at 1142 off- 
premise outlets (convenience stores, supermarkets, liquor stores and drug stores). They found that liquor stores had the highest number of exterior and interior advertisements, with the majority being for beer; independently owned outlets had the most advertising and, specifically, significantly more advertising below three feet from the floor where it was likely to be clearly visible to children; and some evidence of ethnic targeting of alcohol advertisements, by using cultural icons and models of specific ethnic groups, particularly for exterior alcohol advertisements targeting Latinos.

In a study of the correlates of the in-store promotions for beer, based on analysis of supermarket scanner data from 64 market areas across the USA, Bray et al. (2007) found that large-volume units are more likely to be promoted than smaller package sizes. Based on evidence from previous market research that has shown in-store merchandising and promotions can substantially increase beer sales and that purchasing large package sizes may increase total consumption, they concluded that the prevalence of sales promotions for large-volume beer packages may result in increased beer consumption. While this study was limited to a single product type (beer), it is likely that a similar effect would be found for other forms of alcohol (such as ready-to-drink (RTDs) or alcopops, which are generally sold in four-packs, six- packs and cartons) and particularly popular with young people.

Significantly, several recent studies have examined the association between ownership of alcohol promotional items (i.e. the types of branded products that are frequently offered as premiums in alcohol POS promotions) and drinking behaviours. These studies have consistently reported an association between own- ership of promotional items and alcohol consumption in both cross-sectional (Hurtz et al. 2007) and longitudinal studies, with the latter finding that ownership of alcohol merchandise by nondrinkers at baseline is associated with initiation and consump- tion at follow-up (McClure et al. 2006, Henriksen et al. 2008). Given the propensity of young people today to be particularly brand conscious (Beaudoin et al. 2003, Chaplin and John 2005), this is an important area for policy makers.

In 2003, the US Centers for Disease Control and Prevention (CDC) recognised the significance of POS marketing for young people. It released a report on an observational study of POS alcohol marketing conducted during $2000 \square 2001$ across 3961 randomly selected retail alcohol outlets in 329 US communities (Centers for Disease Control and Prevention 2003). Findings included $92 \%$ of stores having interior alcohol advertisements, 44\% having low-height advertisements and 51\% having at least one alcohol-branded functional object. The report concluded that POS alcohol marketing is extensive in certain store types frequented by teenagers and young adults and that public health agencies and policy makers should work towards reducing such marketing due to its potential to increase excessive alcohol consumption and underage drinking.

While there are some significant implications in these studies, they are bound by the cultural context within which they occur. There are significant differences in the culture of alcohol service and regulation in Australia which need to be accounted for, not least the lower drinking age of 18 (compared to the USA 21). There is little research in Australia into the effects of POS marketing on young people, with most of the existing research focused primarily on advertising (Jones and Donovan 2001, 2002, King et al. 2005, van Bueren and Davis 2005, Jones et al. 2008, Jones et al. 2009). To date, there have been only three Australian studies which have specifically examined POS alcohol promotions, all of which were exploratory in nature. Smith et al. (2005) conducted an observational study to quantify the proportion of fridges that were used for RTD products (over $40 \%$ of all glass-door refrigerators across the sample). Two studies, (Jones and Lynch 2007a, b) recorded alcohol POS promotions in bottle shops and licensed venues in the Wollongong (Illawarra, NSW) CBD. In relation to bottle shop promotions (the focus of the present research), the authors identified 17 different promotions across the 7 stores (Jones and Lynch 2007b) and concluded that, given previous research demonstrating the relationship between increased alcohol consumption and both ownership of alcohol-related merchandise and reduced per unit price, it appears that POS promotions may have the potential to further increase alcohol consumption among young people.

This is of particular concern because of the circumstances in which young people buy and consume alcohol, and the lack of regulation around POS promotions in outlets such as bottle shops. Most Australian states currently have guidelines or codes of practice in relation to the promotion of alcohol for on-premise consumption (e.g. pubs and clubs). In New South Wales (the state in which the current research was conducted), the Liquor Industry Code of Practice for Responsible Promotion of Liquor Products provides 
'a framework of practices which are considered acceptable and reasonable' for licensed and registered premises (Department of Gaming and Racing 2002).

However, it is important to note that the regulations and codes of practice relate to on-premise rather than to the off-premise establishments which are the focus of this research. There is currently no similar code of practice or specific regulations relating to POS promotions in off-premise establishments (e.g. bottle shops). The Australian Alcohol Beverages Advertising Code (ABAC) covers retailer advertise- ments (i.e. those that contain information about the products offered for sale and their prices, etc) and states that these 'must comply with the spirit and intent of the Code but are not subject to any process of prior clearance'. However, the Code is silent on the issue of in-store advertising and promotions.

There is clear evidence then, from several decades of research, that alcohol price promotions are associated with increased alcohol consumption, particularly among young people. However, the vast majority of the research that has been conducted has been in the context of establishments that sell alcohol for on-premise consumption. What has been largely neglected in both research and policy is the nature, extent and effects of POS alcohol promotions in bottle shops and liquor stores. The development of policies and regulations in this area needs to be guided by evidence on the effects of different types of POS promotions on alcohol-related attitudes, beliefs and behaviours among young people. There is currently a limited amount of research on the nature of these promotions, and no Australian research on their extent or effects. In this study, we conducted focus groups with young people to examine their recall of, and responses to, alcohol POS promotions, with the aim of understanding the connection between POS promotions and alcohol purchasing behaviour.

\section{Method}

After obtaining approval from the University's Human Research Ethics Committee, we conducted a series of 12 focus groups with young people regarding their recall of, and responses to, alcohol POS promotions. Adolescents (16 $\square 17)$ and young people (18 $\square 25)$ were recruited to participate in focus group discussions; using age and gender criteria to ensure quotas were met for these variables. We included 16- to 17- yearold groups as, although they are under the legal drinking age, evidence suggests many are consumers of alcohol beverages and are exposed to a range of promotions. For example, a recent survey of over 1000 Australian adolescents found that $74.8 \%$ of $12 \square 15$ year-olds and $82.2 \%$ of $16 \square 17$ year-olds recalled seeing alcohol advertising/ promotions in a bottleshop (Jones and Magee, in press). Thus, while the immediate effects of exposure may be more evident among those over the age of 18 years, POS promotions are likely to have both short-term effects (such as influencing purchase requests from those who obtain the alcohol for underage drinkers) and long-term effects (such as influencing brand attitudes and alcohol expectancies).

Focus group discussions were conducted in Sydney (metropolitan area), Wollongong (regional) and Dubbo (rural), with four groups (two male, two female) held in each location, with an overall total of 85 participants. Participants were recruited in one of two ways. Participants aged $16 \square 17$ years were recruited by a commercial recruitment agency, with advertisements placed in local newspapers. Those aged $18 \square 25$ years were invited to participate after being involved in a previous study; with the numbers supplemented by commercial agency recruitment to meet our targets of eight participants in each group. All participants were provided with an information sheet outlining the aims of the study and all provided written consent prior to participation. Other than age and area of residence, there were no specific inclusion/exclusion criteria as the aim was to recruit a broad cross-section of young people; specifically, and consistent with our research ethics approval, potential participants were not asked about their drinking status (drinker or non-drinker). Participants aged $16 \square 17$ years received a $\$ 20$ cash payment and a $\$ 25$ gift voucher, and those aged 18 years and over received a $\$ 50$ cash payment as compensation for their time. All focus groups were facilitated by trained research assistants who were in their early twenties, with groups conducted by a facilitator who was the same gender as the participants, to increase the comfort of the participants in discussing their alcohol-related attitudes and behaviours.

Alcohol is primarily consumed in the social arena. Therefore, focus groups with members from a similar demographic allows for a more 'familiar context within which people's idea's are formed and their decisions made' (Liamputtong and Ezzy 2006, p. 85). Groups were both age specific (i.e. either $16 \square 17$ or 
$18 \square 25$ years) and separated by gender. It was important to separate young people into the two age groups, based on whether they were legally able to purchase alcohol (i.e. over or under 18 years) as the two age groups were anticipated to have different purchasing and consumption behaviours and to be influenced by different factors in their social and physical environment. It was also important to conduct single-gender groups due to the potential for participants' responses to be unduly influenced by the presence of opposite-gender peers.

\section{Discussion guide}

Focus group leaders for each age group initiated discussion on exposure, and response, to POS promotions. After a general discussion about alcohol products and the 'good' and 'bad' things about drinking the facilitator commenced the discussion with: 'Now we are going to talk about different types of promotions for alcohol that you might see at the bottleshop. We're not talking about ads that you might have seen outside the bottleshop, like on television. Have you ever seen a promotion? [PROMPT: free gifts, competitions]'. This was followed by an open discussion of the promotions they recalled (including product types, brands, nature of the promotion, etc). They were then asked 'Have you/someone you know ever bought any products because of a particular promotion? What was the promotion? Why? [PROMPT: what was the prize/gift? What was it worth? What did you have to buy/ do?]'. This was followed by a discussion of whether promotions would influence them to buy a different product (or amount of product) and what types of promotions were the most influential. Finally, they were shown examples of current and past POS promotions collected in the initial research phases. Participants, as part of their discussions, reviewed the promotions and provided feedback regarding their attitudes and behavioural responses towards them; this was both in the context of their recall of the specific promotions and their responses to them and in the context of their 'usual' or likely response to similar promotions. The overall aim of the investigation was to identify any interaction between POS promotions and drinking attitudes and behaviours of young people.

\section{Data analysis}

The focus group audio files were transcribed in full and the transcripts analysed with the objective of understanding the impact of different types of POS promotions on alcohol-related attitudes and behaviours. The approach to analysis was based on conventional content analysis, whereby coding emerges from immersion in the data (Hsieh and Shannon 2005). Thematic analysis was undertaken applying the constant comparison method (Glaser 1965). Initially, the first author and a research assistant each coded the transcripts independently of one another. The discussion guide was used to develop provisional themes; as the aim of the study was to examine recall of and responses to POS promotions, including differences in responses to different forms of promotions. Inductively derived codes were then generated as the analysis continued. Discussion of the researchers' provisional coding schemes continued until agreement was reached on the primary codes. A more detailed hierarchical coding scheme was developed on the basis of this initial analysis. During the coding, detailed code descriptors were developed and revised following further discussion. While we did not conduct frequency counts of responses, each of the coders included descriptors of the consistency of responses $\square$ using words such as 'many' and 'majority' to convey themes or responses that were prevalent across groups and consistent among participants within groups. Responses that were inconsistent with emerging patterns were sought and are reported where they occurred. Recording and continually reflecting on this development ensured transparency in the process. Our analysis identified key themes in attitude and behavioural responses, including differences by gender, age and location (i.e. urban vs. non-urban). These differences, explored in Results section further, are important factors to be considered in the development of specific recommendations aimed at reducing the contribution of POS promotions to alcohol misuse in this target group.

\section{Results}

\section{Drinking behaviours of focus group participants}

All of the participants in the six focus groups aged $18 \square 25$ self-identified as drinkers. All of the participants in the 16- to 17-year-old focus groups conducted in Sydney and Dubbo self-identified as drinkers; but two 
of the male and all of the female participants in Wollongong described themselves as non-drinkers (although many went on to discuss their preferred alcohol drinks and drinking experiences. This could indicate a perception of 'drinker' as someone who consumed alcohol on a heavy or regular basis, as opposed to their own more infrequent consumption. Regardless of the 'identification', we have included their results because the reported behaviour indicates that drinking did in fact occur). The majority of participants in the older groups stated that they buy take-away alcohol once a week or more, and this was generally from bottle shops, with the choice of store being driven by price and location. For the $16 \square 17$ year-olds, price and convenience (location) were also key considerations, with the additional criterion of selecting places they were confident would sell alcohol to them and/or would not ask for proof of age. However, as would be expected, the majority of participants in the younger groups reported that other people purchased their alcohol for them.

\section{Recall of POS promotions}

Unprompted recall of POS promotions among the $18 \square 25$ year-olds was high, with participants in all groups able to spontaneously list a wide range of promotions. Participants in the younger groups were less able to recall details of specific promotions, and those they did recall were generally those that they had seen advertised outside of a bottle shop (e.g. on television, in newspapers/sales catalogues and on external signage).

The most commonly recalled promotions were: price (and price-volume) discounts, free gifts with purchase, competitions and free alcohol with purchase. Participants in the older groups also mentioned promotions which offered discounts on petrol, again from chain stores, although there was a perception in some of the groups that this only applied to the purchase of wine. Examples of such recollections included:

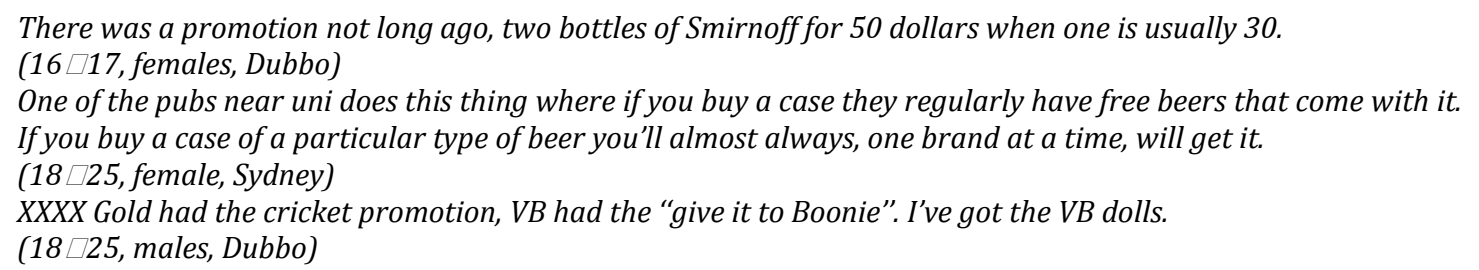

Impact of POS promotions on purchase

When asked whether they would participate in, or be influenced by POS promotions, the immediate response of many participants was that these promotions did not influence their purchasing or drinking decisions (although they may influence other people). However, in most of the groups they then went on to identify promotions which had in fact influenced their purchase decisions. For example:

I bought Cruisers for the big blow up bottles.

Maybe the Boonie, yes I bought a case of VB to get the Boonie. (18 $\square 25$ males, Wollongong)

It was also evident that some promotions - particularly those that were associated with desirable free gifts - were effective in persuading young people to purchase a brand or type of alcohol that they would not usually consume.

\footnotetext{
Oh yeah, actually I was at a New Years Eve party last year and the Jim Beam guys were there and if they saw you with a can of Jim Beam in your hand, they'd come and give you free stuff. I wasn't drinking it but I bought one for the sake of it. They gave me a beach towel, an awesome beach towel and like a bottle cooler. Facilitator: So you went and bought Jim Beam just so they'd see you walking around with Jim Beam? So I'd get the towel, yeah. And a bottle warmer. There was weird hats and stuff... It was a good towel. A massive beach towel.

Facilitator: Did you end up drinking the actual Jim Beam?

Yeah, I mean I still liked it. I wasn't drinking it at the time but I still thought at the time I wouldn't mind one. (18 $\square 25$, females, Sydney)
}

Similarly, many of the participants could recall purchasing greater quantities of alcohol in order to participate in a promotion. 
Facilitator: And what about the Cruisers, did you buy the 2 four packs? Yep.

Facilitator: You just wanted the bag?

Yep.

Facilitator: Do you still have the bag?

Yep, oh, yeh, yeh I do.

Facilitator: And did you go in to get Cruisers that day and just saw it there?

No, I saw it in a magazine... Not a magazine, a catalogue, me and mum were reading it cos I was going to a party that night, so...

(16 $\square 17$, females, Dubbo)

There was an exception to this general trend, with both of the male focus groups conducted in Dubbo (rural area) expressing a consensus view that cost was the primary (or sole) driver of their purchase choice; and, for most participants, the promotion would not override the price consideration.

\section{Price (and price-volume) discounts/Buy some, get some free}

The one form of POS promotion on which there was unanimous agreement was price-promotions, including both reduced price per se and volume purchase discounts. It was evident from the discussion that price-related promotions were the most influential, and males in particular expressed the concept of a 'decision set' from which they choose the cheapest brand.

I think price has a lot more to do with it than...

I generally have a few in mind, a few different brands that are sort of set and I'll just choose the cheapest one... Especially if you're going to get them a lot cheaper.

I wouldn't go in there looking for a deal but as X said I'd go in there with a couple of brands in mind and if one of them had a deal like that it may sway my mind.

(18 $\square 25$, males, Sydney)

It was interesting to note the way that the participants expressed preferences between ' 2 for 1 ' and ' $50 \%$ off promotions (which are theoretically equivalent); and articulated that 'buy one, get one free sounds cheaper' (16 $\square 17$, male, Dubbo). These preferences, and the influence of volume-related price reductions on both purchasing and consumption behaviour, differed across genders and areas of residence. The 18 25 year-olds generally expressed a preference for ' 2 for 1 ', based on the reasoning that they were planning to spend that amount of money anyway, so the additional alcohol was a bonus.

\section{2 for 1.}

Unless you were really poor.

And you have got to think $\square$ Oh I need money for food on the week-end to live then you would go for half price but if you were sort of like oh yeah I have got enough money you would go for 2 for 1 .

If I was going to get a 6 pack and then I saw that it was buy one get one free I would think it was a bonus. I would rather get the 2 instead of half price because I was prepared to spend the money anyway. (18 $\square 25$, females, Dubbo)

However, opinions were divided in the younger female groups, with some participants expressing a preference for 'half-price', based on the reasoning that they could then spend less money and that they would be unlikely to consume all the alcohol if they had double the quantity $\square$ inherent in this was the problem of storage of 'left-over' alcohol without the knowledge of their parents.

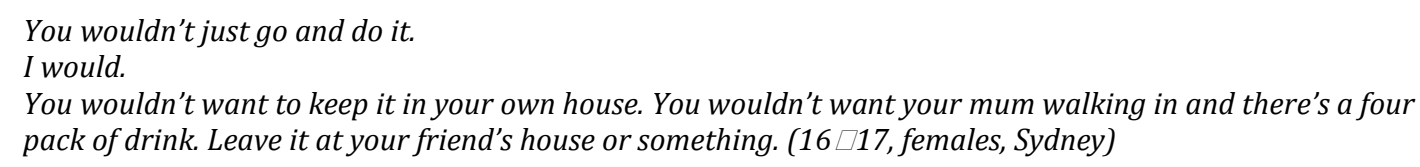

Across all of the groups, participants were fairly consistent in their agreement that volume-related price promotions would impact on their purchase quantities, but divided in their responses as to the influence on consumption.

I'd share it.

I'm pretty greedy so I'd consume it.

I'd probably give it to a mate or save it for another day.

I'd be more inclined to drink both of them because one is free. 


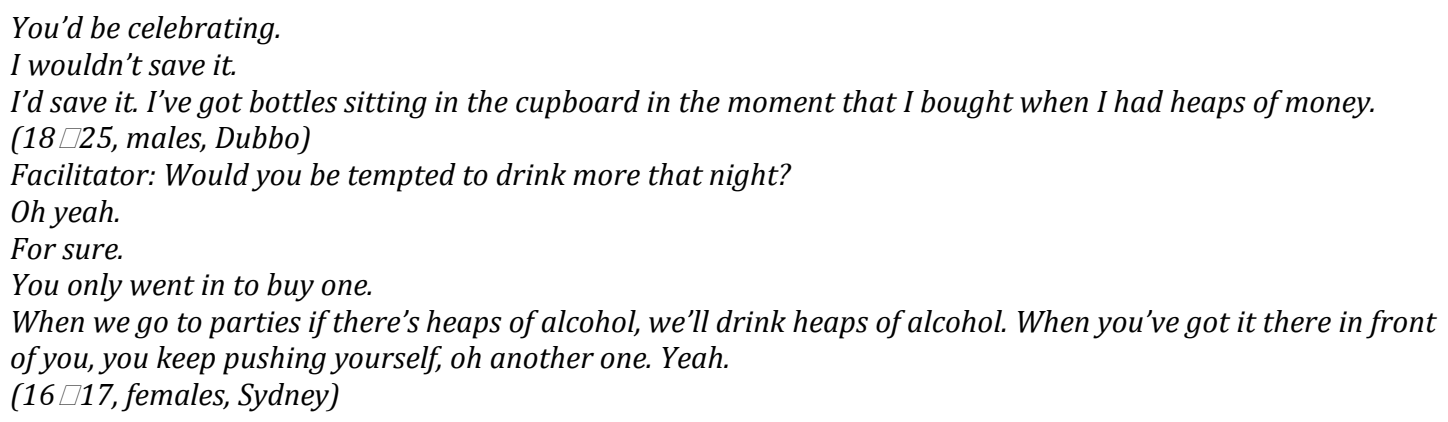

\section{Free gifts with promotion}

The word 'free' clearly resonated with participants, and promotions which offered free alcohol or free merchandise were generally appealing. This related to many of the comments that were made throughout the focus groups about the impulsive nature of many of these purchases, and that being able to walk away with something 'extra' could tip the balance in terms of choosing a particular brand or purchasing a particular quantity.

At the time you do. It's more just a temporary thing, because it's there and you wonder if you need a hat. It's an impulse thing.

(16 $\square 17$, males, Wollongong)

I think everyone is like that. When you go through any brochure and it says "free" you have a look.

Because you're getting something for nothing really.

Just the word "free" and the way your mind reacts to it.

It's like when do you get something for free? (18 $\square 25$, males, Dubbo)

In the majority of the groups, participants expressed the view that they would be willing to increase the amount they purchased (for example, purchasing two 4-packs instead of one) in order to obtain a desirable gift. The only hesitation expressed in relation to this was situation-specific, with participants mentioning that if they were on their way to an event and did not have a car, they would be limited by what they could carry.

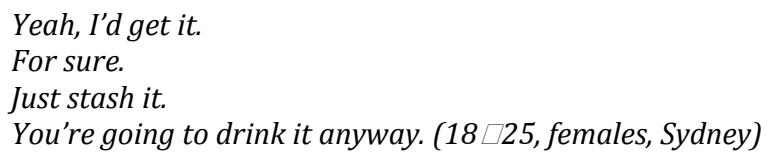

There were age- and gender-related differences in the participants' views on the utility of branded merchandise. Both male and female participants perceived that branded clothing was gimmicky and potentially appealing for males in a 'bonding' or 'competitive' context.

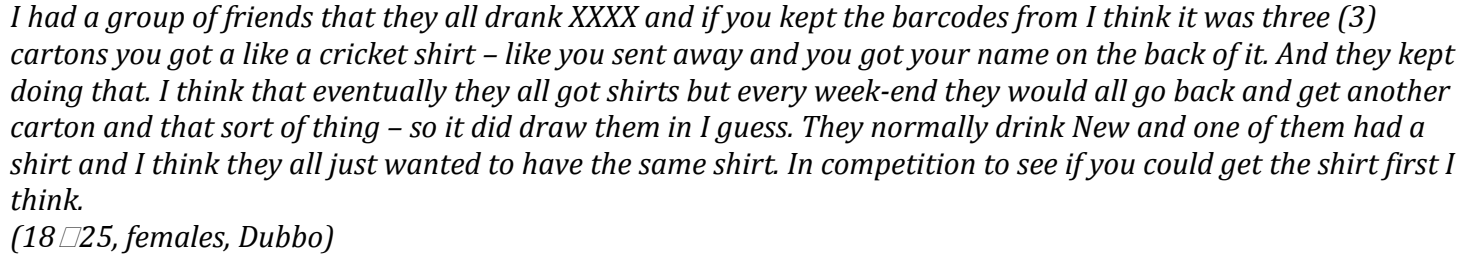
cartons you got a like a cricket shirt - like you sent away and you got your name on the back of it. And they kept doing that. I think that eventually they all got shirts but every week-end they would all go back and get another carton and that sort of thing - so it did draw them in I guess. They normally drink New and one of them had a shirt and I think they all just wanted to have the same shirt. In competition to see if you could get the shirt first I think.

(18 $\square 25$, females, Dubbo)

However, the wearing or carrying of such products by females was seen quite differently by the two age groups. Younger female participants (particularly the 'non-drinkers') perceived ownership of this merchandise to be desirable and to convey social status, whereas for the older females the products were seen as uncool.

Yes, to look cool to your friends

Having alcohol brand stuff

Facilitator: So what does it say about the person?

They're kind of "badder"

It is hard to put into words, there are no rules, it's not anything that is said, it is just common knowledge. 
(16 $\square 17$, females, Wollongong)

It would depend what it was... like it wouldn't be anything cool because it would have something like a Bacardi Bloater on it and you wouldn't be able to wear it because you would feel like a loser.

(18 $\square 25$, females, Dubbo)

\section{Competitions}

Across all of the groups, participants were of the view that competitions were the least influential type of POS promotion. Competitions were perceived as requiring a large amount of effort for an unlikely reward, and participants in all groups expressed a clear preference for reduced price or a tangible gift.

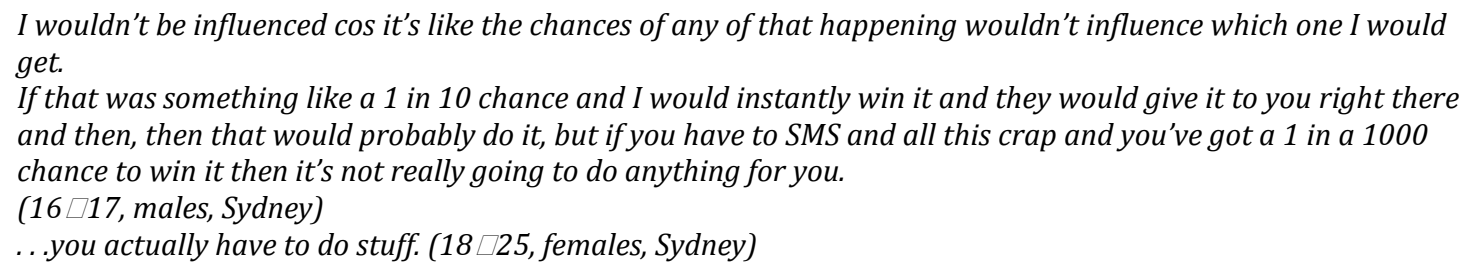

\section{Discussion}

The majority of participants in both the younger (16 $\square 17$ years) and older (18 $\square 25$ ) groups self-identified as drinkers, and generally consumed take-away alcohol at least weekly. Unprompted recall of POS promotions was high, particularly among the older groups, predominantly for price (and price-volume) and free gift promotions. While many participants initially stated that these promotions did not influence their purchasing or drinking decisions, on reflection most of them were able to recall (in considerable detail) promotions they had participated in (for example, a free carry bag with a four-pack of vodka Cruisers). Responses to individual promotions were both item specific (i.e. whether the gift was seen as desirable or as 'tacky') and context specific (e.g. where they were going, whether they were drinking it).

Price promotions were particularly popular among the older groups, especially those that were perceived as giving them more alcohol for their money - with the extra alcohol seen as 'bonus'. Consistent with this, the word 'free' clearly resonated with participants, with promotions which offered free alcohol or free gifts perceived as sufficiently appealing to encourage many participants to purchase a different brand, or a greater quantity, of alcohol. However, they were divided as to whether this would result in increased consumption, with many suggesting that they would consume all that they had purchased but others perceiving that they would, or at least would intend to, keep the 'extra' alcohol for another drinking occasion.

Both in the general discussions and the reactions to specific promotions, competition-based promotions were the least popular (and thus the least likely to influence purchase and consumption decisions) due to the perceived low likelihood of winning and the effort required to participate. This attitude towards competitions was consistent across all of the groups, with participants showing a high level of awareness regarding the low likelihood of success, the lack of real, immediate benefit and the low desirability of the possible prize.

There were differences in responses across the groups that show marked behavioural patterns relating to age, gender and location. Younger respondents were less likely to be motivated by promotions that offered extra volumes of alcohol because of difficulties in storage, and needing to hide alcohol from parents. Regional respondents were markedly more motivated by promotions that offered price reductions, for example, 2 for 1 offers. This was particularly evident in Dubbo, not surprising given it is a large rural town with a number of social and economic problems, including rates of youth unemployment above the state average. POS promotions were also differentially effective along clear gender lines, with males showing higher recall and preference for gifts, whereas females generally thought these were less socially acceptable. Many of the participant's responses also demonstrate that marketing does not act in isolation from other influences on alcohol consumption, including the family. Responses demonstrate that there is a complex relationship between alcohol marketing, family and purchasing and consumption behaviours. 


\section{Limitations}

This was an exploratory qualitative study, with young people from three areas in one state of Australia. We did not collect demographic data from the participants, other than age and gender, and thus cannot comment on the extent to which they are representative of the general population of young people in these regions. Further, while exposure to POS promotions and drinking patterns are similar in other states, caution should be exercised in generalising these findings beyond New South Wales.

As the aim of the present study was to assess awareness of (and responses to) specific types of POS promotions, and the extent to which these responses differed by age and gender, the analysis and reporting of results was structured by this framework rather than by a behavioural theory. Further, as pointed out by Hsieh and Shannon (2005) 'the conventional approach to content analysis is limited in both theory development and description of the lived experience, because both sampling and analysis procedures make the theoretical relationship between concepts difficult to infer from findings' (p. 1280). Thus, we did not seek to collect data on, or interrogate the data, for broader influences on alcohol consumption or product choice beyond the promotions. Future research could usefully examine more nuanced aspects of responses to POS promotions by exploring underlying themes and motivations.

\section{Conclusions}

These findings have clear implications for the regulation of POS alcohol promotions. It is evident that promotions that offer 'free' alcohol or 'free gifts' with the purchase of alcohol are appealing to young people and have clear potential to increase the amount of alcohol they purchase and, for some at least, the amount they consume. While this particular study indicates that there is a link between promotions, purchasing behaviour and the alcohol consumption of young people, the findings indicate that these effects may differ based on age, gender and geographic location - as well as in the relative effects of different promotion types - and these differences would need to be examined further in order to provide evidence that can be used to inform policy and regulation.

It may not be feasible in a free market economy to prohibit the provision of desirable merchandise with the purchase of alcohol; however it may well be feasible to introduce policies that ensure that participation in the promotion does not require the purchase of excessive quantities. There is also an evident need for policies to address the pervasive use of volume discounts, particularly in relation to alcohol products predominantly consumed by young people.

Notes

1. The term 'bottle shop' is the Australian form of the USA 'liquor store', referring to an outlet that specialises in alcohol, which it sells to take-away and consume elsewhere.

2. 'Badder' in this sense refers to being edgy or cool (a 'bad-ass') rather than the original negative meaning of the word 'bad'.

\section{References}

Austin, E.W. and Knaus, C., 2000. Predicting the potential for risky behaviour among those 'too young' to drink as a result of appealing advertising. Journal of health communication, 5, $13 \square 27$.

Babor, T.F., et al., 1978. Experimental analysis of the 'happy hour': effects of purchase price on alcohol consumption. Psychopharmacology, 58, 35 $\square 41$.

Beaudoin, P., Lachance, M.J., and Robitaille, J., 2003. Fashion innovativeness, fashion diffusion and brand sensitivity among adolescents. Journal of fashion marketing and management, 7 (1), $23 \square 30$.

Brabbs, C., 2002. Bottled beer beverages battle to stand out: alcohol brands are using design to make an impact in a cluttered bar. Marketing, February, $27 \square 28$.

Bray, J., Loomis, W.B., and Engelen, M., 2007. Correlates of in-store promotions for beer: differential effects of market and product characteristics. Journal of studies on alcohol and drugs, 68 (2), 220.

British Beer and Pub Association (2002). Point of sale promotions a good practice guide for pub owners and licensees. London: British Beer and Pub Association.

Center on Alcohol Marketing and Youth, 2006a. Still growing after all these years: youth exposure to alcohol advertising on television, 2001 $\square 2005$. Washington, DC: Center on Alcohol Marketing and Youth.

Center on Alcohol Marketing and Youth, 2006b. Youth exposure to alcohol advertising in magazines, 2001 to 2004 : good news, bad news. Washington, DC: Center on Alcohol Marketing and Youth. 
Centers for Disease Control and Prevention, 2003. Point-of-purchase alcohol marketing and promotion by store type: United States, $2000 \square 2001$. MMWR morbidity and mortality weekly report, 52 (14), $310 \square 313$.

Chaloupka, F.J. and Weschler, H., 1996. Binge drinking in college: the impact of price, availability, and alcohol control policies. Contemporary economic policy, 14 (4), 112 $\square 124$. Chaplin, L.N. and John, D.R., 2005. The development of self-brand connections in children

and adolescents. Journal of consumer research, 32 (June), $119 \square 129$.

Chen, M.J., et al., 2005. Alcohol advertising: what makes it attractive to youth? Journal of

health communication, $10,553 \square 565$.

Chipperfield, M., 1996. Popular: the point-of-purchase explosion. Marketing, March, 16 $\square 23$. Coate, D. and

Grossman, M., 1988. Effects of alcoholic beverage prices and legal drinking

ages on youth alcohol use. Journal of law \& economics, 31 (1), $145 \square 171$.

Collins, R.L., et al., 2007. Early adolescent exposure to alcohol advertising and its relationship

to underage drinking. Journal of adolescent health, 40 (6), $527 \square 534$.

d'Astous, A. and Jacob, I., 2002. Understanding consumer reactions to premium-based

promotional offers. European journal of marketing, 36 (11/12), $1270 \square 1286$.

Department of Gaming and Racing, 2002. NSW liquor industry's code of practice-responsible promotion of liquor products: venue fact sheet. Sydney, Australia: Department of Gaming

and Racing.

Dibb, S., et al., 2001. Marketing: concepts and strategies. Boston, MA: Houghton Mifflin Company. Ellickson, P.L., et al., 2005. Does alcohol advertising promote adolescent drinking? Results

from a longitudinal assessment. Addiction, 100 (2), $235 \square 246$

Fleming, K., Thorson, E., and Atkin, C., 2004. Alcohol advertising exposure and perceptions:

links with alcohol expectancies and intentions to drink or drinking in under-aged youth and

young adults. Journal of health communication, 9, 3ロ29.

Garfield, C.F., Chung, P.J., and Rathouz, P.J., 2003. Alcohol advertising in magazines and

adolescent readership. Journal of the American medical association, 289, 2424 $\square 2429$. Gilpin, E., Pierce, J.P., and

Rosebrook, B., 1997. Are adolescents receptive to current sales

promotion practices of the tobacco industry? Preventive medicine, 26, $14 \square 21$.

Glaser, B.G., 1965. The constant comparative method of qualitative analysis. Social problems,

$12,436 \square 445$.

Grossman, M., Chaloupka, F.J., Saffer, H., and Laixuthai, A., 1994. Effects of alcohol price policy

on youth: a summary of economic research. Journal of research on adolescence, 4 (2), 347 $\square 364$. Henriksen, L., et al., 2008. Receptivity to alcohol marketing predicts initiation of alcohol use.

Journal of adolescent health, 42 (1), $28 \square 35$.

Howard, K.A., et al., 2004. Alcohol point-of-purchase advertising and promotions:

prevalence, content, and targeting. Contemporary drug problems, 31 (3), $561 \square 584$.

Hsieh, H.F. and Shannon, S.E., 2005. Three approaches to qualitative content analysis.

Qualitative health research, $15,1277 \square 1288$.

Hurtz, S.Q., et al., 2007. The relationship between exposure to alcohol advertising in stores,

owning alcohol promotional items, and adolescent alcohol use. Alcohol and alcoholism, 42

(2), $143 \square 149$.

Jernigan, D.H., Ostroff, J., and Ross, C., 2005. Alcohol advertising and youth: a measured

approach. Journal of public health policy, 26 (3), 312.

Jernigan, D.H., 2006. Importance of reducing youth exposure to alcohol advertising. Archives

of pediatrics and adolescent medicine, 160 (1), 100.

Jones, S.C. and Donovan, R.J., 2001. Messages in alcohol advertising targeted to youth.

Australian and New Zealand journal of public health, 25, 126 $\square 131$.

Jones, S.C. and Donovan, R.J., 2002. Self-regulation of alcohol advertising: is it working for

Australia? Journal of public affairs, 2/3, 153 $\square 165$. Jones, S.C., Gregory, P., and Munro, G., 2009. Adolescent and young adult perceptions of

Australian alcohol advertisements. Journal of substance use, 14 (6), 335 $\square 352$. Jones, S.C., Hall, D.V., and Munro, G., 2008. How effective is the revised regulatory code for

alcohol advertising in Australia? Drug and alcohol review, 27 (1), $29 \square 38$.

Jones, S.C., and Lynch, M., 2007a. Non-advertising alcohol promotions in licensed premises: does the Code of Practice ensure responsible promotion of alcohol? Drug and alcohol review,

26 (5), 477 $\square 485$.

Jones, S.C. and Lynch, M., 2007b. A pilot study investigating of the nature of point-of-sale alcohol promotions in bottle shops in a large Australian regional city. Australian and New Zealand journal of public health, 31 (4), $318 \square 321$.

Jones, S.C. and Magee, C., in press. Exposure to alcohol advertising and alcohol consumption among Australian adolescents. Alcohol and alcoholism. epub ahead of print. Available from: http://www.ncbi.nlm.nih.gov/pubmed/21733835

Kenkel, D.S., 1993. Drinking, driving, and deterrence: the effectiveness and social costs of alternative policies. Journal of law and economics, $36(2), 877 \square 913$. 
King, E., Taylor, J., and Carroll, T., 2005. Australian alcohol beverage advertising in mainstream Australian media 2003 to 2005: expenditure, exposure and related issues. Sydney, NSW: Department of Health and Ageing.

Kuo, M., et al., 2003. The marketing of alcohol to college students: the role of low prices and special promotions. American journal of preventive medicine, 25 (3), $204 \square 211$.

Levy, D. and Sheflin, N., 1983. New evidence on controlling alcohol use through price. Journal of studies on alcohol, 44, $929 \square 937$.

Liamputtong, P. and Ezzy, D., 2006. Qualitative research methods. 2nd ed. Sydney: Oxford University Press.

McClure, A.C., et al., 2006. Ownership of alcohol-branded merchandise and initiation of teen drinking. American journal of preventive medicine, 30 (4), $277 \square 283$.

Munger, J.L. and Grewal, D., 2001. The effects of alternative price promotional methods on consumers' product evaluations and purchase intentions. Journal of product and brand management, 10 (3), $185 \square 197$.

Osterberg, E., 1995. Do alcohol prices affect consumption and related problems? In: H. Holder and D. Griffith, eds. Alcohol and public policy; evidence and issues. London: Oxford Medical Publications, Oxford University Press, $145 \square 163$.

Pasch, K.E., et al., 2007. Outdoor alcohol advertising near schools: what does it advertise and how is it related to intentions and use of alcohol among young adolescents? Journal of studies on alcohol and drugs, 68 (4), $587 \square 596$.

Smith, A., Edwards, C., and Harris, W., 2005. Bottle shops and'ready-to-drink' alcoholic beverages. Health promotion journal of Australia, 16 (1), $32 \square 36$.

Smith, A., and Foxcroft, D.R., 2007. The effect of alcohol advertising and marketing on drinking behaviour in young people: a systematic review [online]. School of Health and Social Care at Oxford Brookes University. Available from: http://www.aerc.org.uk/documents/pdf/ finalReports/051_Effect_of_alcohol_advertising.pdf [Accessed 28 May 2011].

Smith, L.A. and Foxcroft, D.R., 2009. The effect of alcohol advertising, marketing and portrayal on drinking behaviour in young people: systematic review of prospective cohort studies. BMC public health, 9, 51 $\square 61$.

Snyder, L.B., et al., 2006. Effects of alcohol advertising exposure on drinking among youth. Archives of pediatrics and adolescent medicine, $160,18 \square 24$.

Solley, S. 2000. Stand out in the pub. Marketing, September, 41.

Stacy, A.W., et al., 2004. Exposure to televised alcohol ads and subsequent adolescent alcohol

use. American journal of health behavior, 28 (6), $498 \square 509$.

Sutton, M. and Godfrey, C., 1995. A grouped data regression approach to estimating

economic and social influences on individual drinking behaviour. Health economics, 4 ,

$237 \square 247$.

van Bueren, D. and Davis, J., 2005. Young people's perceptions of alcohol advertising, in relation

to the revised alcohol beverages advertising code. Sydney, Australia: T.S. Research, Research and Marketing Group, Australian Government Department of Health and Ageing. 